\title{
White Knights: Will wind and solar come to the rescue of a looming capacity gap from nuclear phase-out or slow CCS start-up?
}

Bradford Griffin $^{1}$, Pierre Buisson ${ }^{1}$, Patrick Criqui ${ }^{2}$, Silvana Mima $^{3}$

Juin 2013

(1) Enerdata, 47 avenue Alsace Lorraine, 38000 Grenoble, France

(2) Université Pierre-Mendès France, BP 47, 38040 Grenoble, Cedex 9, France

(3) Centre national de la recherche scientifique - Economie du développement durable et de l'énergie, BP 47, 38040 Grenoble, Cedex 9, France

Bradford Griffin (corresponding author): bradford.griffin@enerdata.net

Pierre Buisson: pierre.biusson@enerdata.net

Patrick Criqui: patrick.criqui@upmf-grenoble.fr

Silvana Mima: silvana.mima@upmf-grenoble.fr

\section{Abstract}

In the wake of the Fukushima nuclear accident, countries like Germany and Japan have planned a phase-out of nuclear generation. Carbon capture and storage (CCS) technology has yet to become a commercially viable technology with little prospect of doing so without strong climate policy to spur development. The possibility of using renewable power generation from wind and solar as a nonemitting alternative to replace a nuclear phase-out or failure to deploy CCS technology is investigated using scenarios from EMF27 and the POLES model. A strong carbon price appears necessary to have significant penetration of renewables regardless of alternative generation technologies available, but especially if nuclear or CCS are absent from the energy supply system. The feasibility of replacing nuclear generation appears possible at realistic costs (evaluated as total abatement costs and final user prices to households); however for ambitious climate policies, such as a $450 \mathrm{ppm}$ target, CCS could represent a critical technology that renewables will not be able to fully replace without unbearable economic costs.

\section{Keywords}

nuclear, CCS, phase-out, renewables, climate policy 


\section{Introduction}

Low and zero-emission energy technologies suffered substantial growing pains over the past decade: Japan's Fukushima Daiichi disaster destroyed some countries' confidence in nuclear power (but appears to have had little effect on others); the hopes for a burgeoning carbon capture and storage (CCS) industry have been perpetually on the horizon; wind power increased rapidly but faces grid integration problems; yet the cost of PV solar panels has plummeted thanks to subsidised production in China and subsidised demand in many OECD countries. With all of these factors playing a role in the carbon intensity of our future electricity system, can we afford to rely on renewables to cover a potential supply gap from significant nuclear phase-out around the world or the prospect of CCS technology arriving too late?

Prior to the nuclear disaster at the Fukushima generating station, people were discussing a renaissance of nuclear energy as a clean, affordable, non-emitting power source (Joskow and Parsons 2012). However, with the most severe nuclear accident since Chernobyl bringing the potential safety hazards of nuclear power production to mind, several countries have decided to abandon or delay new facilities. Japan, Germany, and Switzerland have all officially confirmed or accelerated their plans for a nuclear exit since the Fukushima disaster. Other countries, such as the United States, are re-evaluating their existing and proposed projects in light of potentially more stringent safety regulations. This is also the case for developing countries such as China, South Korea, and India although their need for non-emitting electricity is much greater and could override concerns about potential safety risks (Buisson and Arsalane 2012).

The contribution of CCS to future efforts to reduce climate change is uncertain. The technology holds immense promise to allow electricity generation to continue using fossil fuels, even under a carbon price, while reducing the power sector's contribution to atmospheric GHG concentrations through avoided $\mathrm{CO}_{2} \mathrm{e}$ emissions (Finkenrath 2011). Yet despite the perceived technical benefits of CCS, demonstration projects continue to close after several years of operation, often citing uneconomic conditions or uncertain policy environments (AEP 2012, Pioneer Project 2012). If CCS is not available and society must transition quickly away from electricity generation using fossil fuels in order to meet climate targets, 
then the overall cost of transforming our power system could be much higher; for example, to reach the 2005 emission levels by 2050 could be up to $70 \%$ greater without CCS according to the IEA (2010).

Renewable electricity generation capacity is increasing rapidly around the world, both in OECD and developing countries, but wind and solar represented only 4\% of total capacity in 2010. As renewable energy technologies are still in the early stages of development, increases have been due mainly to aggressive adoption policies in a number of countries, such as Germany, China, and United Kingdom. Wind (onshore and offshore) and solar (photovoltaic or concentrating solar) are often cited as the main technologies when considering electricity generated from renewables. Alternatives like biomass can suffer from competition with food production, and energy demand may create perverse incentives in some countries (Mitchell 2008); this limit to potential surfaces for energy crops, as well as the competition for biofuel use, limits the available resources for power production in POLES. Renewables like large hydro and geothermal make considerable contributions in some countries, the prospects for expansion are relatively limited globally. Other possible renewable energy sources like tidal, wave, and small hydro are even earlier in the development cycle than wind and solar, and their potential for contributing to electricity generation in the next several decades is comparatively small. Energy efficiency could also be used to decrease the residual demand from the loss of nuclear capacity or a 'no-CCS' case, however this paper focuses on trying to replace lost supply through other non-emitting sources for a relatively steady demand level.

In this paper we present results from the POLES model for several scenarios simulated for the Energy Modelling Forum 27: Global Model Comparison (Weyant 2013). Four technology cases are simulated to evaluate what role renewables will play while trying to maintain atmospheric carbon budgets of 550 or 450 ppm $\mathrm{CO}_{2} \mathrm{e}$. Technology cases include:

- 'All Technologies' - baseline with no technology restrictions;

- 'Nuclear Phase Out' - no new nuclear capacities are added and existing capacities are retired according to vintage;

- 'Without CCS' - carbon capture and storage is not allowed; and

- No new nuclear and no CCS - note this is not an official EMF27 scenario, but is in line with the EMF27 carbon targets. 
In Section 2, the version of the POLES model used for EMF27 is briefly described, along with relevant modules for this paper. Section 3 discusses the findings, including impacts to the share of renewables if nuclear or CCS technologies are removed from the energy mix, carbon prices and abatement costs, and final user price effects. Finally, the key conclusions from the study are given in Section 4.

Throughout our discussion, we focus on the long-term to 2050. This time frame offers a sufficient length for both CCS and renewable technologies to develop, existing nuclear power plants will have largely surpassed their operating lifetimes and have been retired, and many climate targets use 2050 when setting future emission reductions goals. These factors provide the correct basis when considering the impacts from a nuclear phase-out and/or absence of CCS technology. The advancement of renewables is evaluated based on the shares of wind and solar in the electricity generating mix, the necessary carbon prices and abatement costs to achieve the climate targets under each technology case, and the final user prices that result from the power mixes.

\section{Relevant features of the POLES model}

POLES is a world energy-economy simulation model for the development of long-term energy supply and demand scenarios (European Commission 2006, EC 2012). The POLES model uses a dynamic partial-equilibrium framework, specifically designed for the energy sector but also including other GHG emitting activities. Macro-economic drivers, such as population and GDP growth, are included through exogenous assumptions. The simulation process uses dynamic (year-by-year) recursive modelling, with endogenous energy prices and lagged adjustments of supply and demand by world region.

The POLES model has been developed using a hierarchical framework of interconnected sub-modules at the international, regional, and national levels. A high degree of detail for technological components of the energy system is combined with a strong economic consistency through feedbacks on key components via relative price changes at the sectoral level driven by international 
energy prices. Endogenous model parameters are calibrated on the period 20002010 to include observed preferences and actor behaviour in future forecasts. The current geographic disaggregation of the model incorporates 57 demand regions and 80 supply regions. For each region, POLES articulates four main modules:

- Final energy demand by sector;

- New and renewable energy technologies diffusion;

- Conventional energy and electricity transformation system; and

- Fossil fuel supply (conventional and non-conventional sources).

One world market is considered for oil (the "one great pool" concept), while three regional markets are identified for gas and coal (Americas, Europe \& Africa, and Asia), in order to take into account different cost, market, and technical structures. The model provides technological change through dynamic processes such as the incorporation of two-factor learning curves, which combine the impacts of "learning by doing" and "learning by searching". Price induced mechanisms drive technology diffusion under conditions of sectoral demand and inter-technology competition based on relative costs and merit orders, and allow for consideration of key drivers to future development of new energy technologies. The description of wind and solar power in POLES incorporates potential land surfaces available for power production based on average wind speed and annual solar irradiation. Renewables compete with other technologies to fill a "demand gap" created each year due to total generating stock retirement and electricity demand evolution. A significant amount of intermittent generation affects how electricity systems operate by: requiring more backup power, sometimes spilling electricity which cannot be used, extending the transmission system to accommodate new generation, or even reorganizing the electricity network in order to locally manage supply and demand (local smartgrids). Limits for wind and solar power development due to intermittency are included in POLES and are interpreted as a proxy for grid integration limits, institutional barriers, and energy storage constraints. Model limits include maximum capacities which can be installed based on geography (wind speeds), technology (available backup capacity), and population (rooftop surfaces), as well as separate modelling of network and distributed power capacities. New developments will eventually be needed to better represent intermittency, such as a more detailed capacity credit 
and load factor, explicit link between intermittent generation and energy storage, and load curve alteration due to demand management.

Total nuclear power is the net result of capacity additions from new plants and subtractions due to retirement of existing generating stock. Mid-term (next 5-15 years) capacity additions are calibrated to Enerdata's Power Plant Tracker database, which follows announced, planned, and in-construction power plants. In the long-term, new nuclear additions compete with other technologies for market share. Nuclear capacity is removed from the system based on plant lifetimes and installation date.

Carbon capture and storage technology offers the possibility to generate electricity from fossil fuels, but avoid emitting carbon to the atmosphere. In POLES, gas and coal electricity generation using CCS competes with conventional technologies when determining new generating capacity. For CCS, a premium is applied to the variable costs of conventional technologies to account for capture, transport, and sequestration costs; therefore, non-emitting fossil fuel technology will only appear in simulations that include a price for carbon emissions.

\section{Overview of the Results}

Mitigation strategies requires both a strong electricity demand and a dramatic increase in the share of non-emitting technologies, be it renewables, nuclear power, or generation from fossil fuels with CCS. Many studies have underlined that the decarbonisation of the power sector is the second-largest potential for emission reductions after energy efficiency (Knopf \& alii 2010, Edenhofer 2010, Krey \& Clarke 2011). Implications of different low carbon technologies into the economics of low stabilisation have been largely discussed in many papers (van Vuuren, D.P. \& alii, 2010 ; Knopf \& alii 2010). More recently, the European Union displays its intention to play a leading role in decarbonising its power system by targeting $20 \%$ of its total consumption from renewables by 2020 .

The issue of the role of renewable energy in climate mitigation scenarios is not new. It has been addressed before by other papers. Particularly Krey \& Clarke (2011) have done a synthesis of this issue covering 162 medium to long term scenarios, published during 2006-2010 period, from large-scale energy-economic and integrated assessment models. They argued that "there is little precision in the linkage between renewable global energy deployment and the stabilisation 
goal among the scenarios. This is not surprising given the uncertainty about the evolution of renewable energy technologies, the competitiveness of other options for reducing $\mathrm{CO} 2$ emissions and uncertainty drivers of energy demand". They underline that scenario research could provide more information to unpack this uncertainty.

In fact, last years many progresses have been done on technology performances of renewable technologies, including investment costs. We considered that the update of TECHPOLES database, the improvements in modelling of the renewable energies into the POLES model, and new EMF27 mitigation scenarios which reflects new developments, provide a good reason to handle the question of the role of the renewable energies into the new context. That's why in this section we analyse the role of renewables in selected EMF27 climate mitigation scenarios, in terms of their share of power generation, carbon prices and abatement costs, and final user prices.

\subsection{Share of renewables in power generation}

Renewables contribute around $20 \%$ of world electricity generation today, but their role is expected to expand significantly. Hydropower is currently the principal renewable energy source, representing $85 \%$ of total renewable production. While hydropower continues to expand slightly in absolute terms across most baseline scenarios, its share in total renewable electricity production decreases to around $20 \%$ by the end of the outlook period (Fig. 1). Currently biomass plays a much less important role in the electricity generation than in final consuming sectors; however, its market share should remain stable to 2100 at the current $6 \%$ of total renewable electricity.

Wind and solar power deployment is becoming increasingly widespread, and their role becomes very prominent in some scenarios; for example, representing up to $53 \%$ of total power generation by 2100 in the 450 Nuclear Phase Out scenario.

Fig. 1 Electricity generation shares in baseline, $550 \mathrm{ppm}$, and $450 \mathrm{ppm}$ scenarios: CCS scenarios are not shown for the baseline case since CCS technology is not 
applied in POLES without a carbon value; the 'No nuclear and No CCS' scenario could not be adequately modelled for the $450 \mathrm{ppm}$ case.

Wind and solar PV are considered intermittent production technologies since they are dependent on the local weather, which makes electricity output and timing of production more variable and less predictable. For this reason, the scenarios implement an upper limit to the share of solar and wind supply in the electricity sector. Intermittent renewable electricity reaches around 19\% of total electricity generation in 2100 under constrained solar and wind power scenarios (Baseline 'Constrained Solar and Wind' and 'Conventional Energy Focus'). In a scenario more favourable to renewable technologies ('Baseline with Nuclear Phase Out'), the contributions of solar and wind are maximized with a combined $39 \%$ of total generation. These quantities correspond to the boundaries considered by some studies as manageable with additional flexibility (Krey \& Clarke 2011, Wagner 2012).

Carbon pricing is integral to the competitiveness of intermittent renewables. Both shares and production levels of renewable electricity are much higher in the presence of climate policies and their role increases continuously under carbon taxation. In ' 450 ppm All Tech', by 2100 wind production is multiplied by a factor of five and solar by more than a factor of two when compared to ' $450 \mathrm{ppm}$ Constrained Solar and Wind'.

A strong increase in the share of electricity generation from intermittent renewable sources may pose fundamental challenges to electricity systems. When the contribution of intermittent sources remains limited, the impacts of renewable energy policies on the average production cost and the electricity tariffs are also limited. This contributes to a good level of public acceptance that is generally observed for this type of technological solution. The large increase of renewables resulting from scenarios with strong climate policies brings concerns on how the cost of this solution and its associated backup facilities may affect electricity prices, and subsequently the competitiveness of large energy consumers or the energy budget of households. This has prompted studies and analyses on the impacts of an increasing amount of intermittent generation (Dale et al 2004, Holttinen 2005). Some of the solutions that have been proposed are additional 
interconnections (Zvingilaite et al 2008), more storage (Mariyappan et al 2004, DeCarolis and Keith 2004), and demand response (Strbac 2008).

A significant amount of intermittent generation will impact the way electricity systems operate, the electricity grid's reliability, and the requirements for backup generation capacities or storage. Unless large integrated regional networks - or super-grids - are developed, it will be difficult to take advantage of the potential complementarities in the hourly production profiles of intermittent sources. In order to manage the irregularity of solar and wind energy production individual countries are normally forced to implement "backup" capacities, such as combined-cycle gas turbines (i.e. conventional means of electricity production), which are easily started, but can induce high levels of greenhouse gas emissions. Van der Welle and de Joode (2011) indicate that for the integration of intermittent technologies in power systems there is a wide range of different technical and institutional options available and propose some response options per segment of the electricity system. Examples include technical options in generation (e.g. large-scale energy storage), metering for demand response, and time-dependent pricing for networks and markets.

Currently in the POLES model, capacity limits for intermittent technologies are simulated primarily through available backup capacities (thermal and hydropower). Electricity storage and integrated regional networks will be taken into account in upcoming model developments. The long term production cost of electricity is thus impacted by continuous changes in four main determinants:

- shares of the different power plant categories (intermittent renewables, thermal, nuclear and hydro)

- investments costs by category, according to technology improvement and learning-by-doing effects

- average annual production costs by category, including changes in capacity factors (especially for backup options)

- carbon cost for fossil thermal power plants, with or without CCS

If new nuclear capacity cannot be installed for political or social reasons and a global phase-out occurs, a sizeable portion of non-emitting electricity production will need to be replaced. This situation could occur by country, as for Germany and Japan, or it could occur globally more generally. While it may be less likely 
that a global moratorium on new nuclear capacity will develop, we use the EMF27 'no nuclear' scenarios to evaluate the maximum effect a global nuclear exit would have. In these scenarios, no new nuclear capacity is added and existing plants are retired according to their installation date and lifetimes. For the 'Baseline with Nuclear Phase Out' case, the complete exit from nuclear power is reached around 2060 , with less than $10 \%$ of the current capacity remaining in 2050. Without a price on carbon emissions, there is very little augmentation in the shares of electricity produced from wind and solar due to a progressive exit from nuclear power. ${ }^{1}$ Globally, nuclear capacity stands at $380 \mathrm{GW}$ in 2010 and generates approximately $13 \%$ of electricity. In the baseline, nuclear capacity is $940 \mathrm{GW}$ in 2050 and generates over $11 \%$ of electricity, but as there is no price driver for low-emission technologies in the baseline fossil fuels fill almost this entire gap when nuclear is removed as a power option. In 2050, compared to the 'with nuclear' case wind capacity increases by $1.5 \%$ of total energy, while solar does not increase its shares in a meaningful way.

The 'All Technologies' scenarios have significant quantities of both nuclear and CCS generated electricity. ${ }^{2}$ Shares of electricity production are similar in the 550 and 450 ppm baselines, in 2050: wind (17\%), solar (16\%), nuclear (18\%), CCS (44-45\%). When nuclear is removed, to replace its portion of total electricity production, primarily CCS, wind, and solar increase their shares as opposed to other generation technologies (Fig. 2). Most of the gap is filled by a rapid augmentation of CCS (especially fossil fuel-equipped CCS), which grows to supply an additional $11-13 \%$ of total electricity ( +4.7 to $5.7 \mathrm{GWh})$. Wind and solar production each grow modestly by $1-2 \%(+0.4$ to $0.9 \mathrm{GWh})$.

Fig. 2 Change in world electricity production by technology

CCS technology is not yet viable at the commercial scale and there are many cost and technical unknowns when considering a scale-up, but it offers great promise to help adapt our current fossil fuel based electricity system to a carbon price. To evaluate the complete unavailability of CCS for power generation, we use the

\footnotetext{
${ }^{1}$ Without a carbon price, CCS does not develop in POLES; therefore, we do not consider a 'no CCS' case associated with a baseline (not carbon constrained) scenario.

${ }^{2}$ For the EMF27 standard carbon constrained scenarios (550 ppm and $\left.450 \mathrm{ppm}\right)$, which are presented in this paper, a global carbon market is used with a single carbon price.
} 
EMF27 'no CCS' scenario where carbon capture and storage never becomes a viable technology.

To replace the very large portion of total electricity production supplied by CCS, nuclear and renewables generally fill the gap (Fig. 2). Nuclear in particular grows to supply an additional $26-30 \%$ of total electricity production in $2050(+10$ to 14 $\mathrm{GWh}$ ). Wind and solar production is relatively stable, remaining within $\pm 5 \%{ }^{3}$ By 2100 , with the existing installed nuclear capacity and a $21 \%$ reduction in electricity demand, wind power is generally "crowded out" from the production it provided in the 'baseline' case and actually decreasing from what it would have supplied without the carbon taxation.

\subsection{Carbon prices and abatement costs}

Renewables and energy efficiency will have to play key roles if nuclear or CCS are unavailable for the de-carbonization of the energy system. However, a lack of non/low-emitting technologies in the investment portfolio drives up the marginal abatement cost required to satisfy a global GHG target and despite a technological analysis of the feasibility of alternative options, an economic assessment is also necessary to understand the economic viability of these solutions (Table 1). In the 'All Technologies' case, to satisfy a carbon limit of $550 \mathrm{ppm}$, the marginal abatement cost calculated by the POLES model reaches $260 \$ / \mathrm{tCO}_{2} \mathrm{e}$ in 2100 ; to satisfy a 450 ppm target, the marginal cost is far higher even allowing for all technology choice. ${ }^{4}$ Assuming a global nuclear phasing-out policy, the carbon price is comparable to the 'all technologies' case for both the $550 \mathrm{ppm}$ and 450 ppm scenarios.

The absence of CCS in the electricity portfolio appears much more critical in cost terms, even for a scenario with a 550 ppm $\mathrm{CO}_{2}$ e limit. In 2050, the calculated carbon prices to be compatible with carbon objectives are 3-5 times higher than the 'all technologies' case. By 2100 , the costs rise very steeply to impractical levels. The carbon price by the end of this scenario must be high enough to

\footnotetext{
${ }^{3}$ Despite an overall decrease in the 'no CCS' case of electricity production from wind relative to the baseline, wind still maintains or increases its market share of total electricity produced.

${ }^{4}$ All prices included in this analysis are provided in constant 2005 USD.
} 
essentially remove all carbon from the power sector and is no longer really acting as a tax, but as a ban.

CCS technology offers the particular advantage of negative emissions when trying to meet atmospheric $\mathrm{CO}_{2} \mathrm{e}$ concentration targets. When combined with biomass, CCS can effectively extract carbon from the atmosphere and sequester it underground. Considering that our global $\mathrm{CO}_{2} \mathrm{e}$ concentration has already reached 390 ppm $\mathrm{CO}_{2} \mathrm{e}$ in 2012 , to achieve a $450 \mathrm{ppm}$ goal, or even a $550 \mathrm{ppm}$ target, the potential for negative emissions will be extremely useful. If this technology is unavailable because of problems with technological scale-up or difficulty finding appropriate storage locations, then negative emissions will likely be impossible. ${ }^{5}$ A very high carbon price is therefore necessary to compensate for the loss of CCS while remaining within the $\mathrm{CO}_{2} \mathrm{e}$ target limits. Part of this high carbon price is due to the lack of available energy storage or grid management technologies, both in the POLES scenarios and at commercial scale in today's industry. Over the very long term to 2100 , innovations will certainly provide new options which could provide more flexibility, so the results included here should be viewed as an upper limit if given only today's technologies.

Table 1 Carbon prices for various $\mathrm{CO}_{2} \mathrm{e}$ limits

\begin{tabular}{|cc|ccc|}
\hline \$05/ $/ \mathrm{tCO}_{2} \mathrm{e}$ & & Baseline & $\mathbf{5 5 0} \mathbf{~ p p m}$ & $\mathbf{4 5 0} \mathbf{~ p p m}$ \\
\hline \multirow{3}{*}{ All Technologies } & $\mathbf{2 0 3 0}$ & 0 & 160 & 240 \\
& $\mathbf{2 0 5 0}$ & 0 & 260 & 830 \\
& $\mathbf{2 1 0 0}$ & 0 & 260 & 1850 \\
\hline \multirow{3}{*}{ Nuclear Phase Out } & $\mathbf{2 0 3 0}$ & 0 & 180 & 280 \\
& $\mathbf{2 0 5 0}$ & 0 & 260 & 800 \\
& $\mathbf{2 1 0 0}$ & 0 & 270 & 2020 \\
\hline \multirow{3}{*}{ Without CCS } & $\mathbf{2 0 3 0}$ & 0 & 230 & 860 \\
& $\mathbf{2 0 5 0}$ & 0 & 870 & 4130 \\
\hline \multirow{2}{*}{ Nuclear Phase Out } & $\mathbf{2 1 0 0}$ & 0 & 4100 & 14000 \\
and Without CCS & $\mathbf{2 0 3 0}$ & 0 & 380 & $\mathrm{n} / \mathrm{a}$ \\
& $\mathbf{2 1 0 5 0}$ & 0 & 2020 & $\mathrm{n} / \mathrm{a}$ \\
\hline
\end{tabular}

\footnotetext{
${ }^{5}$ Geo-engineering options could provide methods to collect $\mathrm{CO}_{2} \mathrm{e}$ from the atmosphere; however potential technologies are at a theoretical level of development today.
} 
The carbon price multiplied by the necessary mitigation effort to reach a climate target (abatement cost) gives a sense of the economic burden that will be felt. As indicated in Fig. 3 below, abatement costs remain below 4\% of GDP for the "All Technologies' and 'Nuclear Phase Out' cases, with dramatically higher costs associated to the 'Without CCS' case; CCS appears as a key technology to maintain abatement costs at a manageable level. This high cost is mainly related to a lack of guaranteed peak load generating choices if fossil fuel technologies are omitted from the energy mix; POLES must use very high carbon prices to drive renewables to displace fossil fuels as peak load options. Biomass-combustion technologies can only supply a small portion of this need given their limited potential.

These results from the POLES model show that to some extent, nuclear and CCS act as substitutes for each other for reaching carbon constrained objectives. It is therefore very interesting to study the impact on costs of both technologies being unavailable (the electricity system relying much more strongly on renewables or energy efficiency measures). Compared to an 'All Technologies' case, turning off both nuclear and CCS in the model leads to an abatement cost in 2100 of $10.8 \%$ of total world GDP to reach a $550 \mathrm{ppm}$ concentration target (more than double the 'Without CCS' case). Electricity prices are unrealistically high by the end of the simulation causing up to $35 \%$ reduction in total demand for electricity. Setting aside the extremely high prices, we can focus on the power mix which results from a combined nuclear phase-out and unavailability of CCS. In 2100, renewables fill the gap through solar (increase of $23 \%$ to $36 \%$ of total electricity production), biomass ( $10 \%$ to $22 \%$ ), hydro (6\% to $12 \%)$, and hydrogen fuel cells $(1.5 \%$ to $8 \%)$. As with the 'Without CCS' case, wind power is crowded out due to demand reduction and higher costs relative to the other technologies (wind's share falls from $23 \%$ in the 'All Technologies' case to $16 \%$ in the no nuclear or CCS case).

Fig. 3 Total world abatement costs for various $\mathrm{CO}_{2} \mathrm{e}$ limits

We were unable to adequately model the 'Nuclear phase out and No CCS' case for a $450 \mathrm{ppm}$ concentration target. The extremely high costs associated with this scenario make results from POLES using a fixed GDP forecast unrealistic. Already in the 'Without CCS' case, total abatement costs are at $15 \%$ of world 
GDP. When nuclear power is also unavailable, the abatement costs rise to impractical proportions of world GDP, and a true paradigm shift of the energy system that moves beyond supply and demand responses would be necessary in these circumstances (European Commission 2011). The POLES model, as well as most other energy-economy models, does not endogenously account for such a total change to the energy and material systems underpinning our economy.

\subsection{Final user prices}

While Governments are increasingly concerning themselves with planning for a low-carbon future, they also need to ensure a secure and affordable power system for their citizens, especially in rapidly developing economies where access to reliable electricity provides significant economic and health benefits (World Bank 2008). Translating the abatement costs shown above into final user prices can help give a sense of the impact available technology options will have on society. While different power generation options will have direct climate outcomes, electricity prices to consumers will have strong economic impacts. It is important to note that POLES is a partial equilibrium model that uses an exogenous GDP forecast. As such, prices cannot influence the global economic evolution. Therefore, the prices shown in the following sections, especially the very high prices for some scenarios, should be considered with this in mind.

As an example, we consider the evolution of power prices in the residential sector in non-OECD countries to see how the different configurations may impact the access to electricity in these countries.

Fig. 4 Average Non-OECD residential electricity prices

Power prices are forecast to increase during the next decades, with a steep rise during the next 15 years (Fig. 4). Indeed with a growing carbon taxation and a strongly emitting power mix (mostly relying on coal), non-OECD countries will be affected strongly.

In the 'All Technologies' scenario, power prices in the constrained cases increase by approximately $50 \%$ by 2100 compared to the baseline case. The absence of nuclear exacerbates this trend, but it is broadly similar to the 'all technologies' scenario: a steeper increase in the mid-term due to rising carbon taxation and 
decreasing prices over the long-term as the power mix decarbonises. The 'Without CCS' scenario presents a very different forecast; power prices rise from $0.07 \$ / \mathrm{kWh}$ in 2010 to $7-9$ times that level in the constrained cases by 2100 . Again, it should be noted that these prices are in the absence of innovative technologies to manage peak load power, either through energy storage from renewables or grid management to allow better integration of intermittent sources. ${ }^{6}$ In the mid-term, prices remain within the World Bank's (2008) estimate of willingness-to-pay for rural electrification $(0.10-0.40 \$ / \mathrm{kWh})$, but as prices continue to rise connecting the world's poor in rural areas may be increasingly unaffordable and residential electricity prices of this scale could be crippling for developing countries over the coming decades. While electricity prices on the scale of $0.20-0.30 \$ / \mathrm{kWh}$ are already observed in some OECD countries, those societies have already benefited from decades of access to much cheaper power. Many non-OECD countries, especially in sub-Saharan Africa, are struggling to provide basic power services to their citizens. Innovative solutions will need to be found for a global climate agreement limiting $\mathrm{CO}_{2} \mathrm{e}$ emissions that does not cripple non-OECD countries' ability to develop their economies.

\section{Conclusions}

The outlook for using wind and solar power to replace a large nuclear phase-out or the absence of CCS technology in the power system appears to be relatively limited. If a complete nuclear phase-out is conducted around the world (i.e. no new nuclear capacities are added and existing plants are retired according to vintage), even a stringent climate target (450 ppm) can still be met since either renewables or CCS could replace the lost base load power. However, if CCS is unavailable, even a more modest climate target $(550 \mathrm{ppm})$ will be very expensive to achieve since there are currently few alternative options for guaranteed peak load power other than fossil fuels.

The current version of the POLES model is limited when considering fundamental changes to the electricity generation system, like breakthrough technologies for non-emitting peak load generation; with the extremely high electricity prices shown in this study as a result. The high carbon prices and electricity costs

\footnotetext{
${ }^{6}$ Residential electricity prices in POLES are primarily set through peak load rates.
} 
presented in this paper for the 'Without CCS' cases can be seen as an upper limit of the costs engendered by a very strong decarbonisation scenario; this finding highlights the need for investments in alternatives to fossil fuel peak load power options, like grid interconnection improvements, large-scale electricity storage, and demand side management.

\section{References}

American Electric Power (2012) Corporate Citizenship: Carbon Capture \& Storage.

http://www.aep.com/environmental/climatechange/carboncapture/. Accessed 15 October 2012

Buisson P, Arsalane Y (2012) Perspectives de l'énergie nucléaire : vers un monde bipolaire ?. Revue de l'énergie 605 :janvier-février

Cenovus Energy Inc (2012) Operations: Weyburn.

http://www.cenovus.com/operations/oil/weyburn.html. Accessed 15 October 2012

Dale L, Milborrow D, Slarkc R, Strbacd G (2004) Total cost estimates for large-scale wind scenarios in UK. Energy Policy, 32:1949-1956

DeCarolis JF, Keith DW (2006) The economics of large-scale wind power in a carbon constrained world. Energy Policy. 34(4):395-410

Edenhofer O, Knopfl B, Barker T, Baumstark L, Bellevrat E, Chateau B, Criqui P, Isaac M, Kitous A, Kypreos S, Leimbach M, Lessmann K, Magne B, Scrieciu S, Turton H, van Vuuren D (2010) The economics of low stabilization : Model comparison of mitigation strategies and costs. Energy J., 39:11-48

Eurelectric (2012) Energy roadmap 2050 : A EURELECTRIC response paper

European Commission (2006) WETO-H H $_{2}$ World Energy Technology Outlook - 2050

European Commission (2011) PACT: Pathways for Carbon Transition

European Commission (2012) POLINARES: EU Policy on Natural Resources

Finkenrath M (2011) Cost and performance of carbon dioxide capture from power generation. International Energy Agency Working Paper

Holttinen H (2005) Optimal electricity market for wind power. Energy Policy. 33:2052-2063 
International Energy Agency (2010) Technology roadmap: Carbon capture and storage

Joskow PL, Parsons JE (2012) The future of nuclear power after Fukushima. MIT Center for Energy and Environmental Policy Research CEEPR WP 2012-001

Knopf B, Endhofer O, Barker T, Bauer N, Baumstark L, Chateau B, Criqui P, Held A, Isaac M, Jakob M, Jochem E, Kitous A, Kypreos S, Leimbach M, Magné B, Mima S, Schade W, Scrieciu S, Turton H, van Vuuren D (2010) The economics of low stabilisation : Implications for technological change and policy. In: Hulme M, Neufeld H (eds) Making climate change work for us. Cambridge University Press, Cambridge, pp 291-318

Krey V, Clarke L (2011) Role of renewable energy in climate mitigation: a synthesis of recent scenarios. Climate Policy 11, p. 1-28.

Mariyappan J, Black M, Strbac G, Hemmi K (2004) Cost and technical opportunities for electricity storage technologies. Project GreenNet, Work Package 3 Report. http://www.greennet-europe.org. Accessed 15 October 2012

Mitchell D (2008) A note on rising food prices. World Bank Development Prospects Group, Policy Research Working Paper 4682

MNP (2006) Integrated modelling of global environmental change. An overview of IMAGE 2.4. Bouwman AF, Kram T, Klein Golfewijk K (eds). Netherlands Environmental Assessment Agency (MNP). Bilthoven, The Netherlands

Pioneer Project (2012) Pioneer Project. http://www.projectpioneer.ca/. Accessed 15 October 2012

Shell Canada Ltd (2012) About Quest: Quest Carbon Capture and Storage.

http://www.shell.ca/home/content/can-

en/aboutshell/our_business_tpkg/business_in_canada/upstream/oil_sands/quest/about_quest/.

Accessed 15 October 2012

Strbac G (2008) Demand side management: Benefits and challenges. Energy Policy. 36:44194426

van der Welle AJ, de Joode J (2011) Regulatory road maps for the integration of intermittent electricity generation: Methodology development and the case of The Netherlands. Energy Policy 39(10):5829-5839 
van Vuuren, D.P., Isaac, M., Den Elzen, M.G.J., Stehfest, E., Van Vliet, J., 2010, 'Low stabilization scenarios and implications for major world regions from an integrated assessment perspective', Energy Journal 31(Special issue), 165-192.

Wagner F (2012) Feature of an electricity supply system based on variable Input. IPP report. MaxPlanc-Institut für Plasmaphysik. p 49

Weyant J (2013) Energy Modeling Forum 27: Global Model Comparison Exercise.

http://emf.stanford.edu/research/emf_27_global_model_comparison_exercise/. Accessed 23 April 2013

World Bank (2008) The welfare impact of rural electrification: A reassessment of the costs and benefits

Zvingilaite E, Jacobsen HK, Poza Sanchez E, van der Welle AJ (2008) Overview of optimal market response options: Identification and analysis of market response options. Report D5 of the RESPOND project. http://www.respond-project.eu/. Accessed 15 October 2012 